\title{
Leading Groups To Create Healthy Culture Through Accomplishing Tasks Aligned To Strategy
}

Jeffrey R. Moore, Anderson University, USA

Lee E. Kizer, Southern Wesleyan University, USA

B. Philip Jeon, Southern Wesleyan University, USA

\begin{abstract}
This study examined the link between the consistency of self-evaluation versus peer-evaluation of managers' skills and the level of relational stress in an organization and was based on two models: (a) the Competing Values Framework (CVF), which measures different management skills of individuals in an organization, and (b) the Healthy versus Toxic Organization Model, which focuses on the stress level in partnerships. The researchers hypothesized that the lower the stress in the organization, the more consistent the results will be between self-evaluation and peerevaluation. In an empirical analysis, the researchers found that the relationship was most visible in the area of managers' facilitator skills. With strong facilitator skills, managers can lead their organizations effectively and stay focused on maintaining strategic alignment. The study also examined how management skills could be most effective in developing a healthy work culture.
\end{abstract}

Keywords: culture; alignment; skills; evaluation; stress

\section{INTRODUCTION AND LITERATURE REVIEW}<smiles>[C]1C=CCCC=C1</smiles>

uccessful companies exist when employees and other stakeholders interact in a healthy manner while focused on the accomplishment of critical tasks. How to develop a positive culture while maintaining strategic alignment among the stakeholders was the subject of this research. Corporate directors' behaviors were assessed by their peers in order to determine positive culture, level of stress, and strategic alignment. This study examined the link between the consistency of self-evaluation versus peer-evaluation of a manager's supervisory skills and the level of stress between individuals in the organization. The researchers hypothesized that the lower the stress in the organization, the more consistent one's self and peer management skill evaluation will be. This research also determined how management skills might be most effective in developing a healthy work culture.

A company spends a significant part of its budget on employee training. This training is aimed at developing new skills that will improve the effectiveness and efficiency in accomplishing tasks. Essential skills to possess in the company are social skills, which are needed to interact effectively with others (Cote \& Miners, 2006). Cote and Miners reported that employees with high cognitive intelligence out-perform those with low cognitive intelligence. Employees with low cognitive intelligence perform at higher levels if they also have a high level of emotional intelligence. Emotional intelligence is the appraisal and expression of emotions in oneself, appraisal and recognition of emotions in others, regulation of emotions in oneself, and use of emotions to facilitate performance (Goleman, 1995). Cote and Miners' findings demonstrated that higher emotional intelligence tends to compensate for low cognitive intelligence in regards to job performance (Baron \& Markman, 2003).

Witt \& Ferris (2003) investigated the relationship between conscientiousness, the accomplishment of tasks, and social skills. Conscientiousness, one of the five major dimensions of personality, is defined by an individual who has competence, order, dutifulness, achievement, self-discipline and deliberation as part of his personality (Costa \& McCrae, 1992). Individuals who are very conscientious showed higher task performance than those who 
are low in conscientiousness and high in social skills. Those who are high in conscientiousness (task) but low in social skills (culture) may come across as unreasonable, authoritarian, demanding, inflexible, and this may lead others in their teams to avoid working with them, creating negative work environments (Witt \& Ferris). Employees who were low in social skills with high levels of conscientiousness actually reduced job performance. Witt and Ferris concluded that the importance of social skills on the job in completing tasks is essential.

Social scientists have studied the dynamics of groups and their impact on the individual and the organization. Forsyth (1999) refers to a group as a collection of two or more individuals who share a common goal, have a stable pattern of relationships and perceive themselves as being a group. Benne and Sheats (1948) noted that roles within the group tend to be differentiated between task-oriented roles and relations-oriented roles (socioemotional). The categorization of task and relations roles in looking at group dynamics within the organization informed the current research study.

In the mid 1970s, Hare (1976) examined the impact of cohesiveness and the lack of cohesiveness in groups. Groups, which lacked cohesiveness and where individuals did not like each other, often worked against each other. Current research shows that highly cohesive groups are ones where individuals accept the group's goals, help work towards meeting goals, have a sense of belonging to the group, and have higher performance (Beal, Cohen, Burke, $\&$ McLendon, 2003). Data on group cohesiveness indicate that cohesiveness is a positive trait as individuals in cohesive groups enjoy belonging to the group, accept and accomplish the group's goals, are much less absent from their jobs and have less voluntary turnover (Aronson \& Mills, 1959; Cartwright, 1968; George \& Bettenhausen, 1990; Long, 1984).

Strategic alignment is the developing, evaluating, and implementing of actions that will enable a company to reach its long-term objectives. This is done through the development of a mission, vision, policies and plans, followed by an allocation of resources to implement these. Early researchers in the discipline of strategic management included Chandler (1962); Selznick (1957), with the SWOT analysis; Ansoff (1965), with gap analysis; and Drucker (1954), with managing by objectives (MBO). Pascale and Athos (1981) claimed the reason for Japanese corporate success in the 1970s resulted from their superior management techniques. They divided these techniques into seven aspects, known as the McKinsey $7 \mathrm{~S}$ model. This model argued the need for alignment of strategy with structure, systems, staff, style (culture), skills, and shared values.

Peters and Waterman (1982) examined the keys to excellence in organizations. Collins and Porras (1994) conducted empirical research on what makes great companies and found that successful companies encouraged and preserved a core ideology that nurtures the company. Geus (1997), the former CEO of Shell Gasoline, identified four key traits of companies that had prospered for more than fifty years: (a) sensitivity to the business environment, (b) cohesion, (c) tolerance, and (d) decentralization. Each of these traits depends on the ability to build relationships internally or externally. Kaplan and Norton (2006) are known in the field of management for their research on alignment issues within the organization. Their approach has been to take the business strategy and develop a balanced scorecard and strategic map to align the different group and department efforts and performance. When one sees an organization that is dysfunctional and underperforming, the lack of alignment is readily apparent.

\section{Conceptual Models}

Two conceptual models were used as the basis for this research. The Competing Values Framework (CVF) was developed to measure the management skill of individuals in an organization (Quinn et al., 2007). Secondly, the Healthy versus Toxic Organization Model was utilized because it measures the stress in partnerships from a task as well as a culture dimension (Moore, 2006).

CVF has been used extensively in research on organizational and leadership effectiveness and has become a tool for teaching management and leadership in universities. The Competing Values Framework is divided into four quadrants representing the Human Relations, Internal Process, Rational Goal, and Open Systems management models (Figure 1). They are associated with the action words collaborate, control, compete, and create, respectively. Within each of these quadrants Quinn noted there are two management roles, bringing the total management roles of the CVF to eight (Quinn et al., 2007). 
(Human Relations Model)

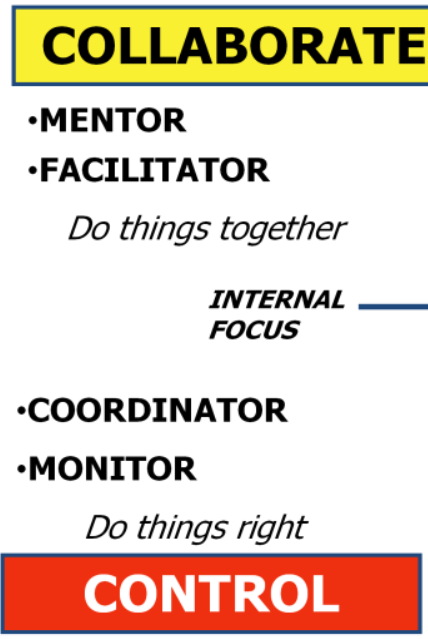

(Internal Process Model)
(Open Systems Model)

\section{CREATE}

-INNOVATOR

-BROKER

Do things first

EXTERNAL

FOCUS

\section{-DIRECTOR}

-PRODUCER

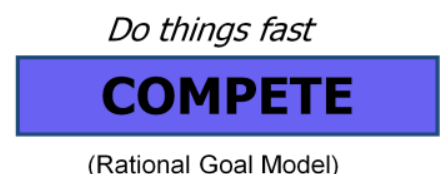

Figure 1: Adapted Competing Values Framework (Quinn et al., 2007)

Benne and Sheats (1948) noted that roles within the group tend to be differentiated between task-oriented roles and relations-oriented roles. Managers have two main responsibilities. The first is for their unit or department to be efficient and effective at accomplishing their goals. Secondly, managers must balance their departments' needs with the overall goals of the organization. This is accomplished through organizational alignment and adaptation of their unit or departmental goals.

The Healthy versus Toxic Organization Model stems from research on virtue and survival behaviors in an organization (Moore, 2006). Data show when virtue behaviors of truth, vision and service were present in organizational partnerships, growth was present. Inversely, when survivalist behaviors of deception, use of fear, pride or greed were present in organizational partnerships, toxicity was present. Stress in an organization, either internal or external, distorts a department's behavior to adapt and cope with the stress and interdepartmental dysfunction.

The Competing Values Framework, with the Strategic Alignment Model and the Healthy versus Toxic Organization Model, combine to clarify some of the organizational stress and dysfunction in the organization. Intuitively, the relationship between healthy partnership behaviors and strategic alignment on organizational goals and priorities can be seen. As relationships thrive in healthy partnerships, strategic alignment is improved and organizational goals are achieved. Inversely, as relationships become toxic and survivalist, relationships deteriorate and organizational goals are lost to more immediate personal or departmental goals. When there is a sustained unhealthy toxic culture developed, silos are created (refers to the imagery of isolated work units which do not communicate and are hostile one to another), and the organization loses its strategic focus and effectiveness. For example, a sales department is in the open systems model and is essential to the company in securing new business and sales. However, the sales department must also be concerned about the success of the operations department, which is found in the rational goal model quadrant. If the sales department does not take into consideration the operation's departmental goals and constraints, it risks creating an unhealthy and toxic culture by selling products that meet its specific sales department goals but are the difficult to produce and thus damage the operations departmental goals. Stress and conflict would therefore arise and silos develop between the sales and operations department because they are competing one against another, each believing the other is a barrier to departmental goals. In an organization there will always be stress and competing demands for resources and accomplishment of goals. However, if this normal organizational stress is dealt with in a healthy fashion, the organization will work as a team and achieve its goals and objectives. The Competing Values Framework provides a method to look at specific feedback from peers and compare it to the self-assessment of each department. Based on a scientific way of approaching these differences, a road map for organizational effectiveness can be established. 


\section{METHODOLOGY}

The data for this research were collected in a small manufacturing company in South Carolina with 200 employees. The chief executive officer (CEO) opened his company to the researchers in order to understand the relationship between healthy and toxic organizational behaviors and their impact on organizational effectiveness. The company is comprised of six departments (i.e., sales, operations, engineering, quality, human resources and finance). The directors of these departments are called the executive leadership. Before administering the surveys, the researchers trained the executive leadership in the CVF and Healthy versus Toxic Organization models. This step was essential in order to develop a common language and a way to consistently evaluate themselves and each other. The training was completed through two quarterly off-site training sessions.

\section{Survey Instruments}

Three survey instruments were used in data collection: (a) a Competing Values Framework selfassessment survey, (b) a Competing Values Framework peer assessment survey, and (c) an inter-department service evaluation survey to assess the partnership level of another department from a task and a culture dimension. The first survey administered was a self-assessment survey comprised of 36 questions that gives eight scores on a scale of one to seven for each of the eight management skills. A score of seven is high indicating mastery or proficiency in each management skill. The second survey was a peer assessment of another's management skill and comprised of 32 questions that gave eight scores on a scale of one to seven for each of the eight management skills (Figure 2). A score of seven is high, indicating that the manager has achieved mastery or proficiency in each management skill. The third survey was a peer assessment about the partnership with each of the other departments in the organization. Using a scale ranging from one to eight, partnerships are evaluated and two scores are given. The first score is given for level of accomplishment of tasks in the partnership. The second score is given for the level of cohesiveness in culture in the partnership.

Tasks $\quad$ Culture:

\begin{tabular}{|c|c|c|c|}
\hline 8 & We are surpassing our expectations & 8 & $\begin{array}{l}\text { We experience unity, accountability, trust and } \\
\text { contentment }\end{array}$ \\
\hline 7 & $\begin{array}{l}\text { We are achieving most of our shared } \\
\text { goals }\end{array}$ & 7 & $\begin{array}{l}\text { We experience acceptance, transparency \& } \\
\text { commitment }\end{array}$ \\
\hline 6 & $\begin{array}{l}\text { We are cooperating and beginning to } \\
\text { meet shared goals }\end{array}$ & 6 & $\begin{array}{l}\text { We engage in constructive conflict (no personal } \\
\text { attacks nor passive aggressive behavior) }\end{array}$ \\
\hline 5 & $\begin{array}{l}\text { We have a shared plan \& are working } \\
\text { together }\end{array}$ & 5 & $\begin{array}{l}\text { We are open to listen to esch other but need to } \\
\text { improve on team problem solving }\end{array}$ \\
\hline 4 & $\begin{array}{l}\text { We are disorganized \& have no shared } \\
\text { plan }\end{array}$ & 4 & $\begin{array}{l}\text { We have a lack of harmony and lack of } \\
\text { cooperation }\end{array}$ \\
\hline 3 & We are not very committed to each other & 3 & We work only by the rules \\
\hline 2 & I just want to get by & 2 & I do my job - you do your job \\
\hline 1 & One partner does not care about results & 1 & One partner says do it my way \\
\hline \multicolumn{2}{|c|}{ Tasks: Quality of Service: } & \multicolumn{2}{|r|}{ Culture: Quslity of Service: } \\
\hline 1. & \multicolumn{2}{|l|}{ Effectiveness } & 1. Shows respect \\
\hline 2. & \multicolumn{2}{|l|}{ Responsiveness } & 2. Truthful \\
\hline 3. & \multicolumn{2}{|l|}{ Correctness } & 3. Positive in resolving problems \\
\hline & $\begin{array}{l}\text { 3.1. Completeness/incompleteness } \\
\text { 3.2. Consistency }\end{array}$ & & $\begin{array}{l}\text { 3.1. Healthy conflict around issues } \\
\text { 3.2. Supportive \& helpful }\end{array}$ \\
\hline & 3.3. Traceability & & 3.3. Consistent in feedback \\
\hline & 3.4. Provably correct & & \\
\hline
\end{tabular}

Figure 2: Inter-departmental Customer Survey 
The first and second surveys can be compared to see the accuracy of the department's self- perception versus its peers' perception. These results can also be used to evaluate its organizational alignment with respect to its organizational fit on the CVF wheel. Each department should be strong within the quadrant that it represents. Deviations from the norm can be observed.

In the organization, department directors should score high in the following roles/quadrants:

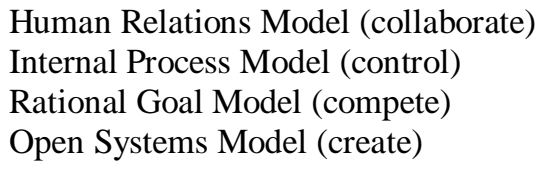

Human Resource department Finance \& Quality departments Operations department Engineering and sales departments

In order to represent graphically the results of the third survey, a scale was developed to clarify the division between healthy and toxic organizational dynamics and is based on Lencioni's (2002) five dysfunctions of a team model (Figure 3). Based on the scores from the survey, departments can be placed on the pyramid, clarifying the realities of the departments in the company. Scores that represented a toxic and dysfunctional organization ranged between 1 and 4 (i.e., $1=$ highly toxic, $4=$ toxic). Scores that represented a healthy and functional organization ranged between 5 and 8 (i.e., $(5=$ healthy, $8=$ very healthy and cohesive).
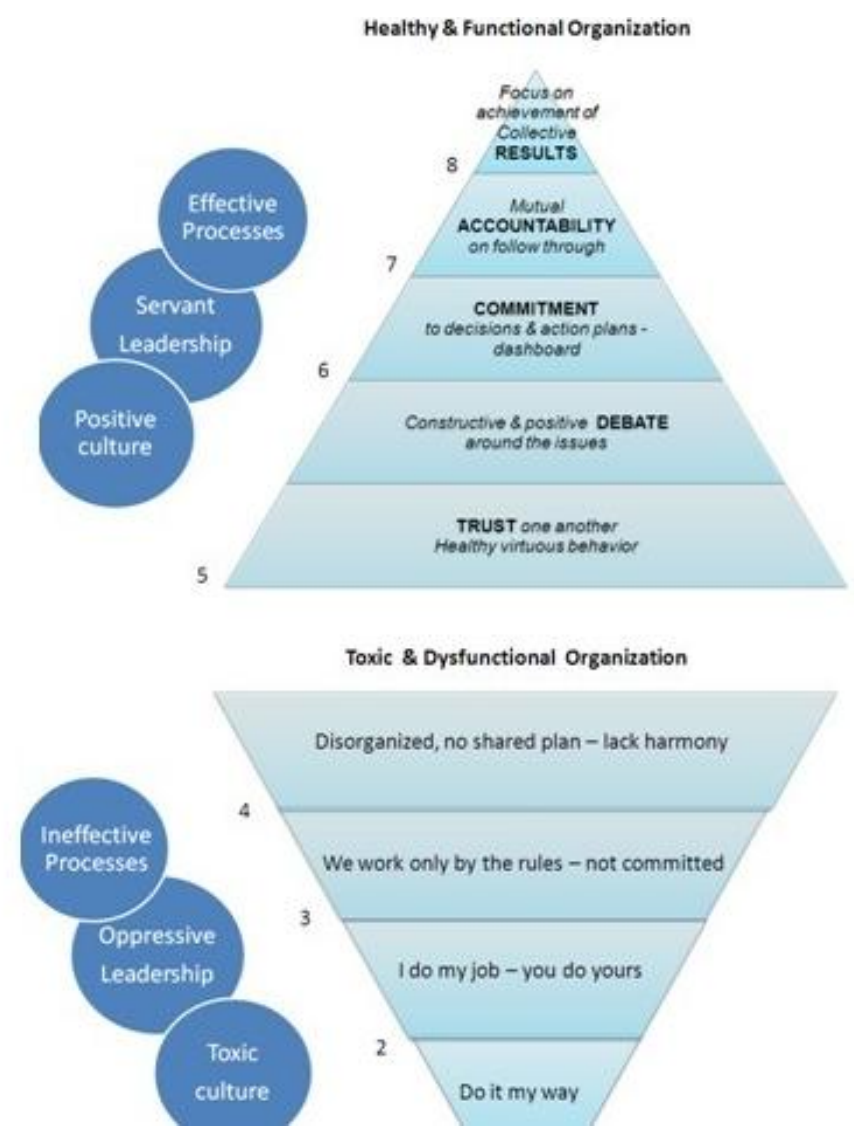

Figure 3: The Division between Healthy and Toxic Organizational Dynamics (based on Lencioni's 2002 Five Dysfunctions of a Team Model) 


\section{FINDINGS}

The data for this research are presented in three parts: (a) the differences and correlation between the department manager's self-evaluation and his peer evaluation of management skill; (b) the measurement of the stress level, evaluated by peers, in terms of task and culture; and (c) the correlation between the first and second sets of data.

Table 1 shows the difference between the self-assessment and peer assessment of eight management roles for each department manager. A negative difference indicates that the peer assessment was lower than the selfassessment. While this table shows where the discrepancies exist between self and peer evaluations, a manager's strength or weakness cannot be measured by these differences.

Table 1: Differences between Self Perception and Peer Perception of Management Skill

\begin{tabular}{|c|c|c|c|c|c|c|c|c|c|c|c|c|c|c|c|c|}
\hline & \multicolumn{4}{|c|}{ Human Relations Model } & \multicolumn{4}{|c|}{ Open Systems Model } & \multicolumn{4}{|c|}{ Rational Goal Model } & \multicolumn{4}{|c|}{ Internal Process Model } \\
\hline & \multicolumn{2}{|c|}{$\underline{\text { Facilitator }}$} & \multicolumn{2}{|c|}{ Mentor } & \multicolumn{2}{|c|}{$\underline{\text { Innovator }}$} & \multicolumn{2}{|c|}{$\underline{\text { Broker }}$} & \multicolumn{2}{|c|}{ Producer } & \multicolumn{2}{|c|}{$\underline{\text { Director }}$} & \multicolumn{2}{|c|}{ Coordinator } & \multicolumn{2}{|c|}{ Monitor } \\
\hline & $\overline{\text { Peer }}$ & Diff. & Peer & Diff. & $\overline{\text { Peer }}$ & Diff. & Peer & Diff. & Peer & Diff. & Peer & Diff. & Peer & Diff. & Peer & Diff. \\
\hline Sales & 4.3 & -1.7 & 3.9 & -2.1 & 5.5 & -0.5 & 6.3 & -0.4 & 5.2 & -0.8 & 4.5 & -0.9 & 4.5 & -0.1 & 5.6 & 0.4 \\
\hline Operations & 4.5 & -1. & 4 & -0 & 4.9 & -0 & 5.4 & 0.4 & 4. & -0.9 & 4.6 & -0.2 & 4 & -0.2 & 5.1 & 0.1 \\
\hline Engineering & 4.8 & -1.4 & 5.2 & 0.5 & 5.1 & -0.9 & 4.6 & 0.1 & 4.5 & -1.3 & 4.5 & -0.7 & 4. & 0.7 & 5.5 & 1.8 \\
\hline Quality & 5.5 & 0.7 & 5.9 & 1.9 & 4.9 & 0.9 & 5.5 & 0.5 & 5.0 & 0.2 & 5.2 & 0.8 & 5.2 & 0.8 & 5.6 & 1.1 \\
\hline Human Res. & 4.9 & -0.4 & 4.4 & -1.8 & 4.6 & -0.2 & 5.4 & 0.9 & 4.6 & -0.6 & 5.0 & 0.8 & 5.1 & 0.5 & 4.2 & -0.8 \\
\hline Finance & 5.4 & -1.0 & 6.2 & -0.8 & 4.9 & -0.6 & 5.5 & -0.2 & 5.3 & -0.9 & 5.4 & -1.0 & 5.9 & -0.5 & 6.0 & -0.5 \\
\hline Purchasing & 5.5 & -0.5 & 6.3 & -0.7 & 5.2 & 0.2 & 6.3 & -0.2 & 5.4 & -0.2 & 5.4 & -1.1 & 5.8 & 0.8 & 5.6 & -0.9 \\
\hline
\end{tabular}

The sales, engineering, and quality managers have two or more scores that are considerably different from their peers' perception. Furthermore, the quality manager underestimated her ability in all eight roles. Finally, the researchers observed that the sales and finance manager overestimated their abilities in almost all eight roles, and the sales manager was not perceived by his peers as being as effective in the human resource quadrant.

In order to determine the perceived strength of a manager's skill, scores of 5.8 to 7.0 were considered strengths. In the facilitator, innovator, producer, and director roles, none of the managers scored a 5.8 or above. In the mentor role, the purchasing, quality, and finance managers scored a 5.8 or above. In the coordinator role, the purchasing and finance managers scored a 5.8 or above. In the broker role, the purchasing and sales managers scored a 5.8 or above. Finally, in the monitor role, the finance manager scored a 5.8 or above.

Taking the difference of self-assessment versus peer assessment of management skills with a rating of 5.8 or above indicates the following information. Scores varying more than 1.5 will be noted as significant. Using the CVF model in the organization, department directors should score high in the following roles/quadrants: (a) Human Relations Model (mentor \& facilitators), (b) Human Resource Department, (c) Internal Process Model (coordinator \& monitor), (d) Finance and Quality Departments, (e) Rational Goal Model (producer \& director), (f) Operations Department Open Systems Model (innovator \& broker), and (g) Engineering and sales departments.

Table 2 illustrates the alignment or lack of strategic alignment of the departments in regard to their perceived management strengths. The strongest alignment exists in the company when the department's perceived management strength is in the appropriate strategic area. This table notes with a + each department's perceived management role strength and a - for a perceived management weakness. In the secondary columns entitled strategic alignment, the strategic area of needed management strength is noted with a + where a low score ranges from 0 to 4.4, a neutral score ranges from 4.5 to 5.7, and a high score ranges from 5.8 to 7.0. Overall, three of the seven managers scored 5.8 and above in peer evaluation on mentor skills, showing that this is a top management strength for these managers. A manager who is a good mentor is desirable for a company which endeavors to create a collaborative culture where team building and communicating effectively are valued. These collaborative skills are essential in the high pressure environment of manufacturing where the company faces constant changes because some of the pressure might be coming internally from managers of other departments who tend to show traits of a dictator rather than a facilitator. 
Table 2: Strategic Alignment of Each Department with Peer Perception

\begin{tabular}{|c|c|c|c|c|c|c|c|c|c|c|c|c|c|c|c|c|}
\hline & \multicolumn{4}{|c|}{ Human Relations Model } & \multicolumn{4}{|c|}{ Open Systems Model } & \multicolumn{4}{|c|}{ Rational Goal Model } & \multicolumn{4}{|c|}{ Internal Process Model } \\
\hline & \multicolumn{2}{|c|}{ Facilitator } & \multicolumn{2}{|c|}{ Mentor } & \multicolumn{2}{|c|}{ Innovator } & \multicolumn{2}{|c|}{ Broker } & \multicolumn{2}{|c|}{ Producer } & \multicolumn{2}{|c|}{$\underline{\text { Director }}$} & \multicolumn{2}{|c|}{ Coordinator } & \multicolumn{2}{|c|}{ Monitor } \\
\hline & $\overline{\text { Peer }}$ & S.A. & Peer & S.A. & $\overline{\text { Peer }}$ & S.A. & Peer & S.A. & Peer & S.A. & Peer & S.A. & $\overline{\text { Peer }}$ & S.A. & Peer & S.A. \\
\hline Sales & - & & - & & & + & + & + & & & & & & & & \\
\hline Operations & & & - & & & & & & & + & & + & - & & & \\
\hline Engineering & & & & & & + & & + & & & & & & & & \\
\hline Quality & & & + & & & & & & & & & & & + & & + \\
\hline Human Res. & & + & - & + & & & & & & & & & & & - & \\
\hline Finance & & & + & & & & & & & & & & + & + & + & + \\
\hline Purchasing & & & + & & & & + & + & & & & & + & + & & \\
\hline
\end{tabular}

It is rather unexpected to find that the quality manager scores high in the mentor skill but not high in the coordinator or monitor skill. The fact that quality managers perform as mentors instead of monitors points to some distortion of alignment in the organization. It may be natural that the sales manager turns out to a good broker, but there appears to be a clash between his perception and the perception of his peers as to the role of an effective facilitator and mentor. His peers seem to think that he is not a good team player, contrary to what he thinks.

It is also interesting to note that the operations, engineering and human resource managers are not seen to have strong management skills by their peers. The operations and engineering departments should be actively pointing the company toward their customers and the external stakeholders; however, if they are focused on developing the facilitator and mentor skills exclusively, they may become distracted and not focus on the market or their customers because of the dominant clan culture.

Table 3 represents the consistency between the department self-perception versus peer perception of management skills. There are two strong negative correlations and two strong positive correlations above the 80th percentile. The strong negative correlation exists in the sales manager assessing himself highly in the mentor and monitor skills, but his peers do not. A strong positive correlation exists where the executive leadership finds the sales director strong in the broker skill and the engineering director strong in the innovator skill.

Table 3: Correlation Coefficient between Self and Peer Perception by Department and Management Skill

\begin{tabular}{lcccccccc}
\hline & \multicolumn{2}{c}{ Human Relations Model } & \multicolumn{2}{c}{ Open Systems Model } & \multicolumn{2}{c}{ Rational Goal Model } & \multicolumn{2}{c}{ Internal Process Model } \\
Facilitator & Mentor & Innovator & Broker & Producer & Director & Coordinator & Monitor \\
\hline Sales & -0.02 & $0.89^{*}$ & 0.58 & $0.81^{*}$ & -0.10 & -0.11 & -0.54 & $-0.81^{*}$ \\
Operations & -0.25 & 0.36 & 0.30 & 0.13 & 0.11 & 0.54 & 0.44 & 0.00 \\
Engineering & 0.31 & 0.20 & $0.80^{*}$ & 0.44 & 0.27 & 0.03 & 0.51 & $0.62^{*}$ \\
Quality & 0.37 & 0.12 & -0.16 & 0.09 & 0.15 & 0.48 & -0.04 & 0.08 \\
Finance & 0.35 & 0.59 & -0.63 & 0.29 & -0.76 & -0.04 & 0.34 & $-0.70^{*}$ \\
Purchasing & $0.77^{*}$ & 0.33 & 0.39 & $0.60^{*}$ & 0.21 & 0.37 & -0.29 & 0.50 \\
\hline
\end{tabular}

Note. * Significant at $\alpha=0.05$ in one-tail test

The sales director is recognized as very strong in the broker role, but his peers perceive him to be low in the internal management skills of coordinator, monitor, facilitator, and mentor. Two explanations can be drawn from the sales director's assessments showing him to be overconfident of his human relations and internal process abilities. First, he could be involved internally in the company with the development of quality, production, and engineering but is not effective in working with these departments in a healthy and cohesive way. Secondly, he could be not involved internally in the company and spending his time with external customers but scoring himself to be strong in the coordinator, monitor, facilitator, and mentor skills. The engineering director is recognized as an innovator but needs to develop these abilities. The finance director is perceived as being a strong manager, internally focused with human relations and internal processes skills. The purchasing director has the strongest leadership abilities among the directors. His peers perceive him to be a very strong facilitator, which is essential in the culture of this company as well as having management strengths in the three of the four management areas.

Another observation included the omission of the human resources department due to insufficient data available to determine a correlation. Not enough peer respondents were provided to give a valid correlation. 
Scores that are closer to eight indicate little or no stress in the partnership. Inversely, scores closer to one are the most stressful and dysfunctional. The middle score is 4.9. Scores 4.9 and lower are defined as having a high level of stress and dysfunctional, while scores above 5.0 are defined as being more functional and less stressful (Table 4).

Table 4: Stress Level Evaluated by Peers

\begin{tabular}{|c|c|c|}
\hline & Task & Culture \\
\hline Sales & 5.0 & 5.4 \\
\hline Operations & $4.1 *$ & $4.1 *$ \\
\hline Engineering & 5.3 & 6.1 \\
\hline Human Res. & 5.3 & 6.3 \\
\hline Quality & 5.3 & 5.9 \\
\hline Finance & $5.9^{*}$ & $7.1 *$ \\
\hline Purchasing & 5.3 & 6.1 \\
\hline Average & 5.15 & 5.78 \\
\hline
\end{tabular}

Note. * indicates outside the $90 \%$ confidence interval for the mean

Scores in the Task and the Culture dimensions are not always the same. A score that is significantly higher in Task over Culture would indicate that the partnership is focused on goals and reaching specific objectives at the expense of developing shared commitment, an effort to solve conflict in a healthy way or develop mutual accountability and transparency. If the score is significantly higher in Culture over Task, the data would suggest that the partnership is focused on creating a healthy culture at the expense of getting specific goals accomplished.

We can observe two interdepartmental relationships that are dysfunctional and stressful and one relationship that is very healthy. The dysfunctional relationships are in the operations and sales departments. In the operations department, relationships are characterized by no shared plan and a lack of harmony. This dysfunction will create a silo mentality between this department and the other departments. The sales relationship is better where some departments report to have a shared plan and open communication. Both of these departments do not benefit from a healthy working environment within the company. These dysfunctions will impact the accomplishment of company objectives and customer expectations. The healthy partnership involves the finance department which has the highest score and the least amount of stress and dysfunction measured by its peers in the company.

Stress scores for the operation and finance departments are out of the $90 \%$ confidence interval, indicating that they are significantly low and high respectively in comparison to other departments. The operations department is low in task as well as in culture revealing a high level of stress within the company. The finance department is high in task as well as in culture indicating a low level of stress within the company.

Finally, it is interesting to note that the purchasing director, the strongest manager, does not have the least amount of stress. The directors with scores above 5.9 are strong in the human relations model as mentors and facilitators, focused on collaborating. Their peers note that they engage in constructive conflict, not engaging in personal attacks or passive aggressive behaviors. It is important to note that their Task scores are higher than the dysfunctional group.

Table 5: Correlation Coefficient between Self and Peer Perception by Management Skill with Stress Level

\begin{tabular}{|c|c|c|c|c|c|c|c|c|}
\hline & \multicolumn{2}{|c|}{ Human Relations Model } & \multicolumn{2}{|c|}{ Open Systems Model } & \multicolumn{2}{|c|}{ Rational Goal Model } & \multicolumn{2}{|c|}{ Internal Process Model } \\
\hline & Facilitator & Mentor & Innovator & Broker & Producer & Director & Coordinator & Monitor \\
\hline $\begin{array}{l}\text { Correlation } \\
\text { Coefficient } \\
\text { (Task) }\end{array}$ & $0.72 *$ & 0.19 & -0.47 & 0.16 & -0.51 & -0.54 & -0.08 & -0.12 \\
\hline $\begin{array}{l}\text { Correlation } \\
\text { Coefficient } \\
\text { (Culture) }\end{array}$ & $0.73^{*}$ & 0.27 & -0.46 & 0.14 & -0.52 & -0.53 & -0.01 & -0.08 \\
\hline
\end{tabular}

Note. ${ }^{*}$ Significant at $\alpha=0.05$ in one-tail test 
The correlation coefficients reported in Table 5 measure the degree of consistency between the results in Table 3 and Table 4. Figures close to 1 in Table 5 would indicate that a stronger agreement between self and peer perceptions of management skill leads to a lower stress level. The threshold value for significance is 0.67 , and a strong positive correlation is found for the facilitator role, which focuses on positive conflict resolution and working in teams. This is consistent for both the task and the culture dimensions.

\section{CONCLUSION}

Successful companies are organizations that have leaders who work to create a healthy working culture as well as focus on accomplishing tasks which are aligned to the mission and strategy. Using a self-assessment and peer assessment of management behavior surveys, the leadership of the organization can determine the health of the culture, level of stress and alignment of its work units. As leaders develop the facilitator behaviors in their departments, stress decreases and tasks are accomplished, improving the health of the culture.

The results of this study show that developing a healthy culture is important to the organization, impacting its ability to accomplish tasks. Directors and employees developing facilitator behaviors will promote a healthy workplace, decreasing stress in the organization and increasing the accomplishment of tasks.

This research points to the validity of using self-assessment and peer assessment of management behavior to locate organization areas of dysfunction and stress. Through the use of training in facilitator behaviors, directors can improve the effectiveness and alignments of their departments and organization.

\section{AUTHOR INFORMATION}

Jeffrey R. Moore received his Ph.D. from the University of Nice Sophia-Antipolis, France where he specialized in international business and organizational development in Eastern Europe after the fall of Communism. He is an Associate Professor at Anderson University in Anderson, SC. Overseas, he has specialized for the past 15 years in entrepreneurial business development between the United States and third world countries, in particular by leading a multi-million dollar revolving loan bank in Romania and the development of a business school in Eastern Europe. His research interest includes topics in the fields of cross-cultural management, ethics and human resource management.

Lee E. Kizer is a Professor of Business at Southern Wesleyan University. He earned his MBA from the University of Arkansas and his Doctor of Science in Human Resource Management from Nova Southeastern University. His publications include cross cultural case studies as well as research in employee performance as a result of training. Dr. Kizer's research interests include topics in the area of employee motivation, employee retention, compensation and job analysis and design. As a former Special Agent for the Federal Bureau of Investigation (FBI), he continues to perform security contract work for the federal government with the Department of Energy, the Department of Defense and the Department of Justice.

B. Philip Jeon is an Associate Professor of Economics at Southern Wesleyan University. Born and raised in South Korea, he has B.A. in Politics and Diplomacy from Hankuk University of Foreign Studies (Seoul, Korea), M.A. and $\mathrm{Ph}$.D. in Economics from University of Kentucky. He has several journal publications in the areas of human capital, labor market earnings, and finance. He regularly teaches Economics, Statistics and Finance in both undergraduate and MBA levels. In addition to his academic position, he currently serves as an Advisory Board Director at a plastics manufacturing company in South Carolina.

\section{REFERENCES}

1. Ansoff, I. (1965). Corporate strategy. New York: McGraw Hill.

2. Aronson, E., \& Mills, J. (1959). The effects of severity of initiation on liking for a group. Journal Abnormal and Social Psychology, 59, 178-181.

3. Baron, R. A., \& Markman, G. D. (2003). Beyond social capital. Academy of Management Executive, 14, 106-111. 
4. Beal, D. J., Cohen, R., Burke, M. J., \& McLendon, C. L. (2003). Cohesion and performance in groups: A meta-analytic clarification of construct relation. Journal of Applied Psychology, 88, 809-820.

5. Benne, K. D., \& Sheets, P. (1948). Functional roles of group members. Journal of Social Issues, 4,41-49.

6. Cartwright, D. (1968). The nature of group cohesiveness. In D. Cartwright \& A. Zander (Eds.), Group Dynamics: Research and Theory (3rd ed.). New York: Harper \& Row.

7. Chandler, A. (1962). Strategy and structure: Chapters in the history of industrial enterprise. New York: Doubleday.

8. Collins, J., \& Porras, J. (1994). Built to last. New York: Harper Books.

9. Costa, P. T., \& McCrae, R. R. (1992). The NEO-PI personality inventory. Odessa, FL: Psychological Assessment Resources.

10. Cote, S., \& Miners, C. T. H. (2006). Emotional intelligence, cognitive intelligence, and job performance. Administrative Science Quarterly, 51, 1-28.

11. de Geus, A. (1997). The living company. Cambridge, MA: Harvard Business School Press.

12. Drucker, P. (1954). The practice of management. New York: Harper \& Row.

13. Forsyth, D. L. (1999). Group dynamics (3rd ed.). Belmont, CA: Wadsworth.

14. George, J. M., \& Bettenhausen, K. (1990). Understanding pro-social behavior, sales performance, and turnover. Journal of Applied Psychology, 75, 698-709.

15. Goleman, D. (1995). Emotional intelligence. New York: Bantam Books.

16. Hare, A. P. (1976). Handbook of small group research (2nd ed.). New York: Free Press.

17. Kaplan, R. S., \& Norton, D. P. (2006). Alignment: Using the balanced scorecard to create corporate synergies. Cambridge, MA: Harvard Business Press.

18. Lencioni, P. (2002). The five dysfunctions of a team. New York: Jossey-Bass.

19. Moore, J. R. (2006). Organizational DNA: Law of virtue. Central, SC: BookSurge.

20. Long, S. (1984). Early integration in groups: A group to join and a group to create. Human Relations, 37 , 311-322.

21. Pascale, R. T., \& Athos, A. J. (1981). The art of Japanese management. New York: Warner Books.

22. Peters, T., \& Waterman, R. (1982). In search of excellence. New York: Harper Collins.

23. Quinn, R. E., Faerman, S. R., Thompson, M. P., McGrath, M. R., \& St Clair, L. S. (2007). Becoming a master manager: A competing values approach. Hoboken, NJ: John Wiley \& Sons.

24. Selznick, P. (1957). Leadership in administration: A sociological interpretation. Chicago: Peterson Row.

25. Witt, L. A., \& Ferris, G. R. (2003). Social skill as moderator of the conscientiousness-performance relationship. Journal of Applied Psychology, 88, 809-820. 